\title{
Hepatoprotective effects of green tea (Camellia sinensis) on diazinon induced liver damage in female mice
}

\author{
Mahnaz Mohammadi ${ }^{1}$, Firozeh KaramBeigi ${ }^{2}$, Zahra Jamshidi ${ }^{3}$, Hoam MohseniKochesfehani ${ }^{4}$ Zeinab Rezaei $^{5}$ \\ ${ }^{1}$ Associate Professor, Faculty of Biological Sciences, Islamshahr Branch, Islamic Azad University, Islamshahr, Iran \\ ${ }^{2}$ MSC, Department of Biology, Kharazmi University, Tehran, Iran \\ ${ }^{3}$ Teacher, Department of Biology, Payamnoor University, Ilam, Iran \\ ${ }^{4}$ Associate Professor, Faculty of Biologyicsl Sciences Kharazmi University, Tehran, Iran \\ ${ }^{5}$ Department of biology, Islamic Azad University, Kazeron Branch, Kazeron, Iran
}

\begin{abstract}
Background: Diazinon increases the production of free radicals and hurts the body tissues. The aim of this study was to evaluate the effect of green tea on tissue and liver enzymes in diazinon-treated rats.

Materials and methods: In this experimental study, 40 NMRI female mice were divided into 8 groups: control group1 did not receive substance; control group 2 and control group 3 received olive oil and saline, respectively, for 7 days; shamgroup 1 received IP injection of diazinon in dose of $60 \mathrm{mg} / \mathrm{kg}$ for 7 days; the sham group 2 and sham group3 received green tea extracts with 200 and $300 \mathrm{mg} / \mathrm{kg}$ for 28 days. Experimental group 1 and 2 were treated with 200 and $300 \mathrm{mg} / \mathrm{kg}$ green tea extract for 28 days, respectively. Diazinon was prescribed with dose of $60 \mathrm{mg} / \mathrm{kg}$ since 14- day for 7 consecutive days in the experimental groups. 48 hours after the last injection, liver tissue was studied for histopathologic examination. The level of liver enzymes activity was evaluated. Data were analyzed by ANOVA.

Results: The activity of liver enzymes in the control group 1 increased compared to the control group, which decreased after application of green tea extract in experimental groups 1 and 2. The histopathological results showed that hepatocytes were destroyed in the control group 1, while tissue necrosis was not observed in experimental groups 1 and 2.

Conclusion: It could be concluded that the consumption of Camellia sinensis normalizes liver enzyme levels and improves liver tissue changes due to diazinon.
\end{abstract}

Keywords: Green tea, Diazinon, Liver, Liver enzyme.

Cited as: Mohammadi M, KaramBeigi, Jamshidi Z MohseniKochesfehani H, Rezaei Z. Hepatoprotective effects of green tea (Camellia sinensis) on diazinon induced liver damage in female mice. Medical Science Journal of Islamic Azad University, Tehran Medical Branch 2019; 29(1): 37-47.

Correspondence to: Mahnaz Mohammadi

Tel: +989127669588

E-mail: mh_mohamadi@yahoo,com

ORCID ID: 0000-0002-3376-2762

Received: 6 Aug 2018; Accepted: 2 Oct 2018 
مجله علوم بزشكى دانشعاه آزاد اسلامى

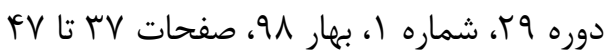

Original

Article

\section{اثر حفاظت كبدى عصاره جاى سبز (Camellia sinensis) در سميت كبدى ناشى از سم ديازينون در موشهاى ماده}

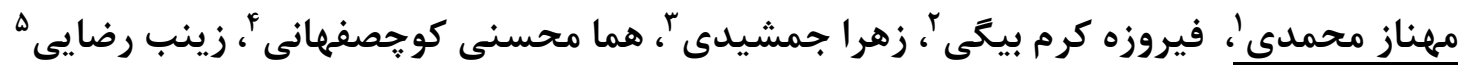

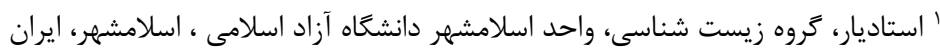

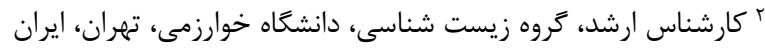

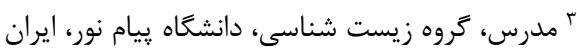

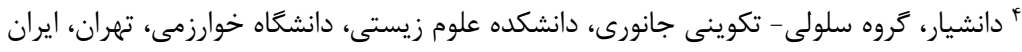

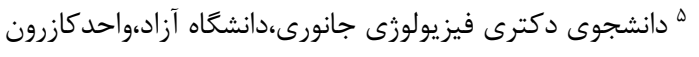

קكيده

سابقه و هدف: ديازينون سبب /فزايش توليد راديكال هاى آزاد و آسيب به بافتهاى بلن ميىشود. هدف /ز /ين مطالعه، بررسى اثر جاى

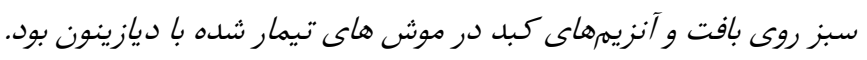

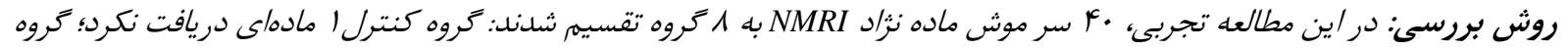

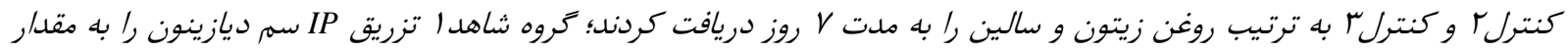

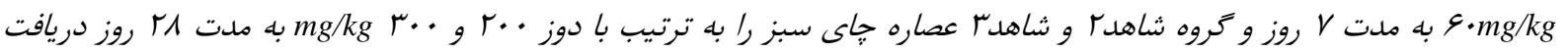

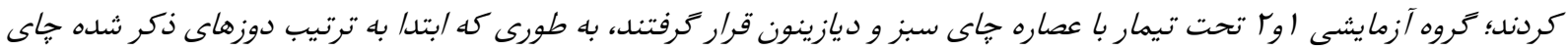

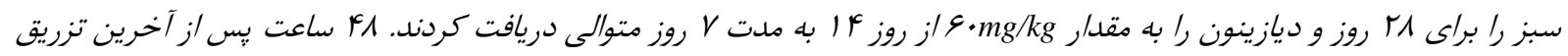

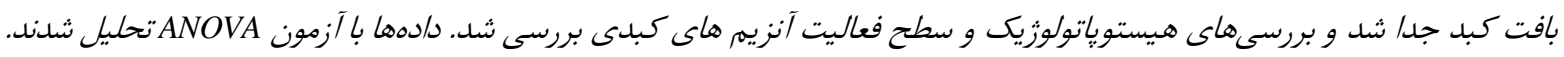

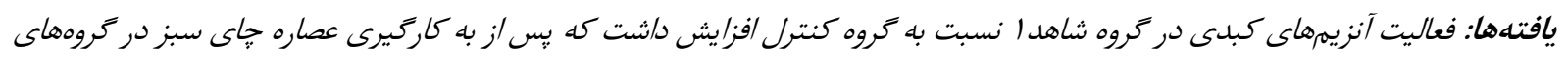

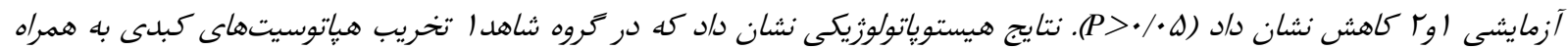

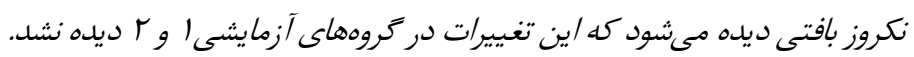

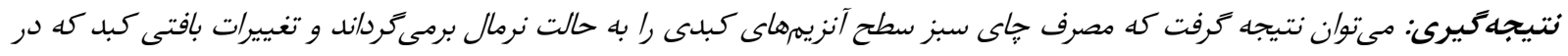

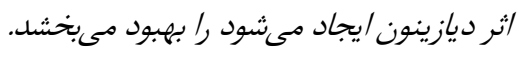

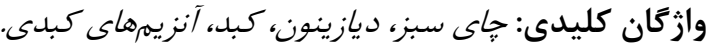

اين تركيبات جندين بـار توسـط عـراق مـورد اسـتفاده قـرار

مقدمه

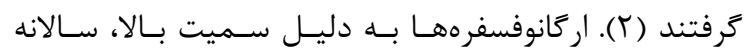

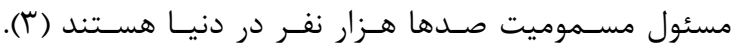
ديـازينون بـا نـام ديميليـت (Dimpylate) و نـام شـيميائي

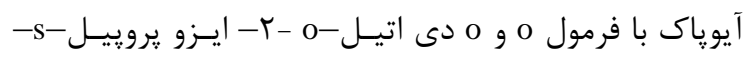

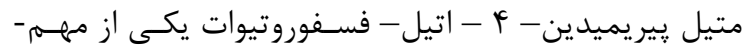

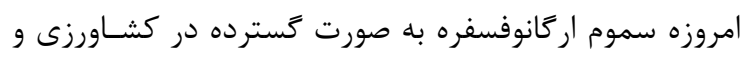

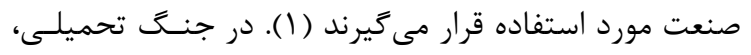

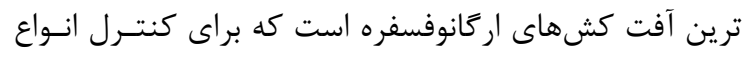

آدرس نويسنده مسئول: اسلامشهر،كروه زيست شناسى، واحــ اسلامشهر دانشعاه آزاد اسلامى، مهناز

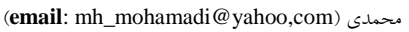
ORCID ID: 0000-0002-3376-2762 تاريخ دريافت مقاله: تV/D/10

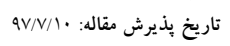


بيانكر آسيب به بافت كبد است (1). (1). آنزيمهاى كبدى شامل

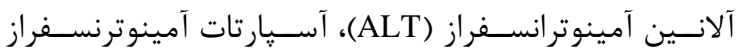

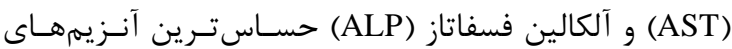
تشخيصى بافت كبد هستند (9 (1). ساختار شماتيك ديازينون

$$
\text { به صورت شكل ( است (·r): }
$$

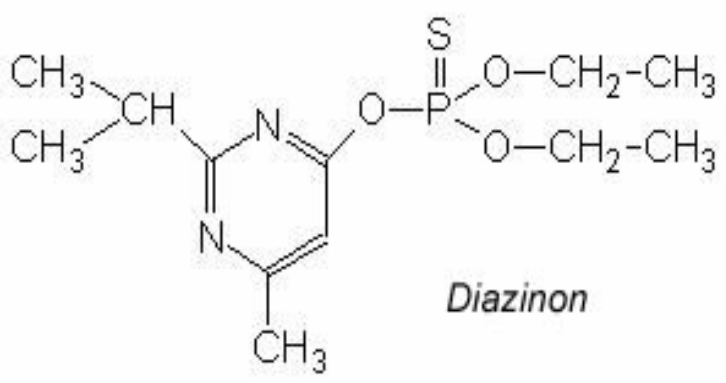

شكل ا. نمايى شماتيك از ساختار ديازينون

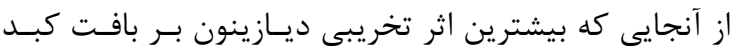

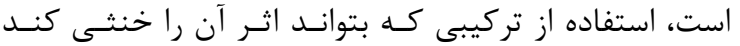

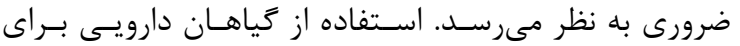
درمان بيمارىها از دير باز در جوامع بشرى مرسوم بوده و وتا حدود نيم قرن يیش كياهان يكى از مههم ترين منابع تـامين

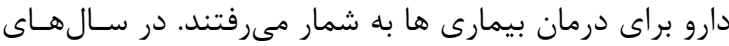

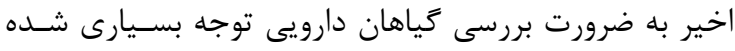

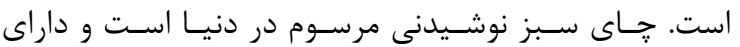

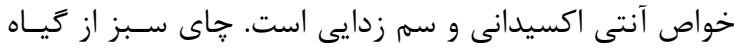

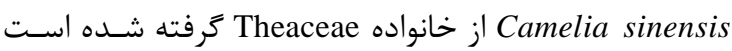

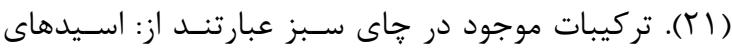
آمينه، كربوهيدرات، مواد معدنى، ليِيد، ويتـامين، تزانتيـك

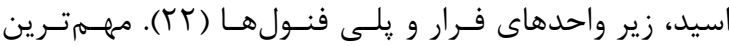

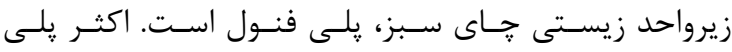
فنولهاى خاى سبز، فلاونولها هستند كه به عنوان كاتهي

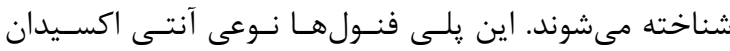

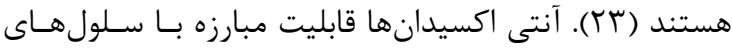
سرطانى را دارند (YY). از ديكر اثرات جاى سباى سبز القاى آيويتوز

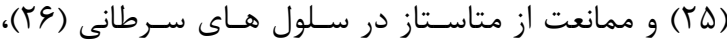

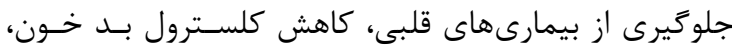

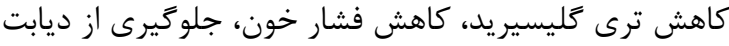

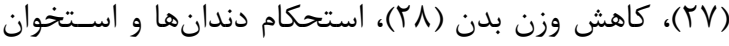

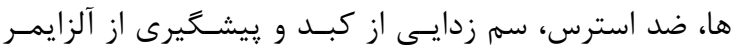

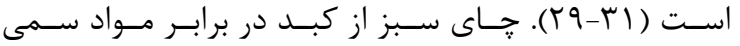

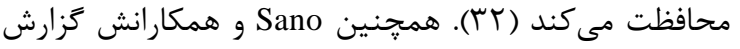
كردند كه كاتجينهاى קاى سبز از يراكسيداسـيون ليييـدى

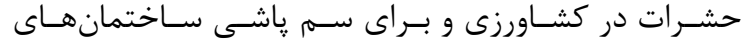
مسكونى مورد استفاده قرار مى گيرد (4). در ايران، ديـازينون به عنوان علت اصلى مرى و مير ناشى از مسموميت شناخته

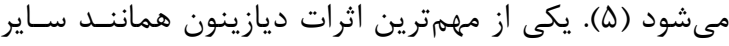

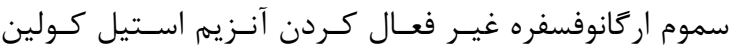
استراز است. مكانيسم اين عمل بدين شرح است كه ديازينون فينون

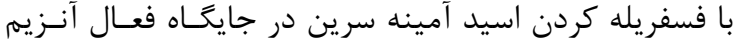

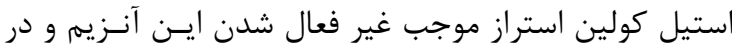

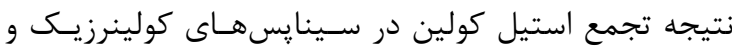

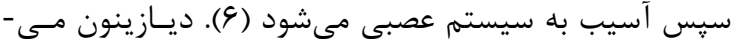

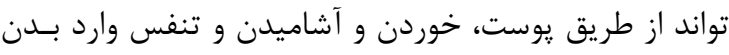
شود (V). ديـازينون بـر سيسـتم عصـبى، سيسـتم تنفسي،

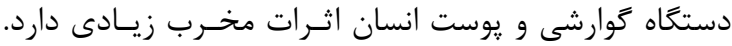

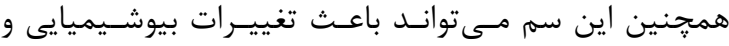

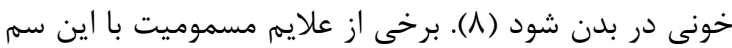

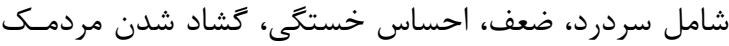

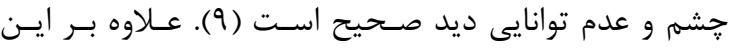

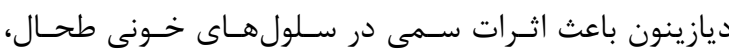
تيموس و غدههاى لنفاوى مىشود (• (). ديازينون به آسـانى

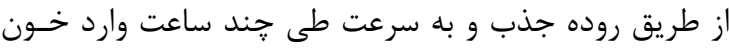

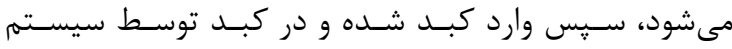

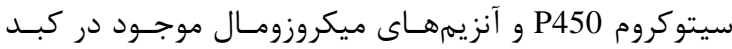
اكسيد شده و از طريق دسولفوراسيون اكسيداتيو به متابوليت فعال سمى خود يعنى ديازوكسان، هيدروكسى ديازوكسـان و دئس

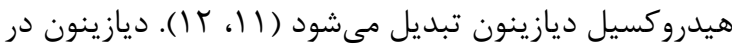

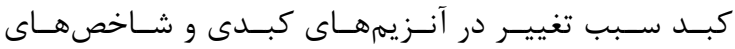

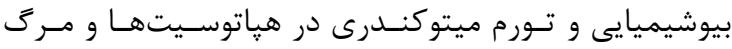

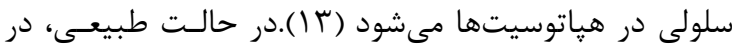
اثر فعاليت و متابوليسم سلولها مقدارى راديكال آزاد توليـد هيد مىشود كه در نهايت توسط عوامل آنتى اكسيدانى موجود در

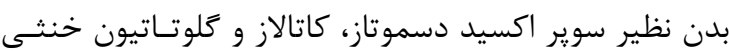
مىشوند. در بدن بين توليد و خنثى شدن راديكال هـاى آزاد آناد

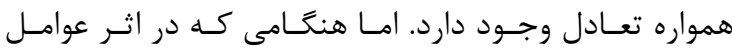
غيرطبيعى توليد راديكال هاى آزاد افزايش مى يابـد، اسـترس

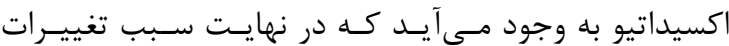

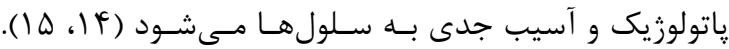
تحقيقات نشان مىدهد كه ديازينون از طريق افزايش توليـد راديكالهاى آزاد باعث استرس اكسـيداتيو و يراكسيداسـيون

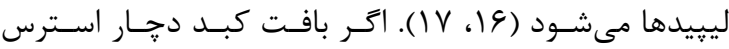

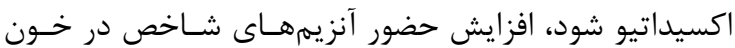




\section{روش عصاره تيرى}

جاى سبز مورد استفاده در اين آزمايش در فروردين ماه سـال

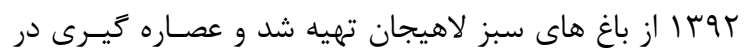

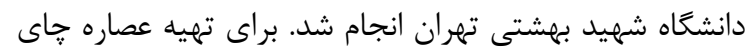

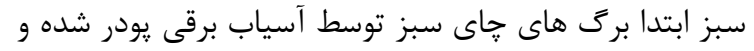

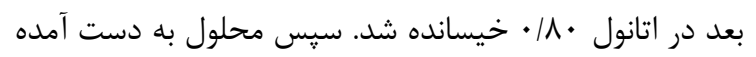

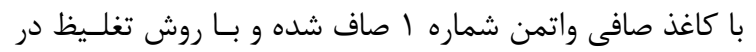

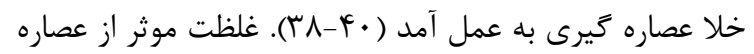

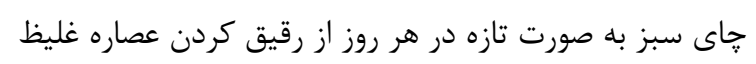

شده با محلول سالين تهيه شد (أع). سم مورد مطالعه

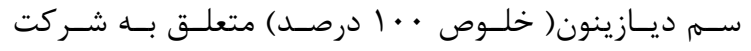
Supelco

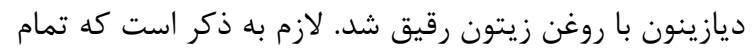

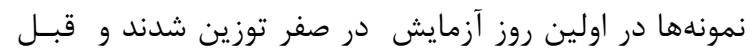

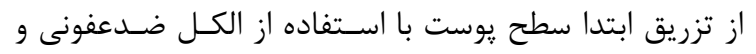

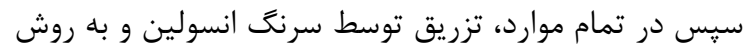

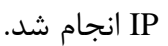
كروههاى مورد مطالعه

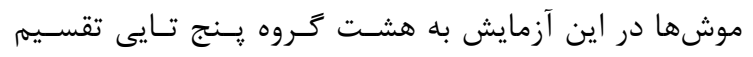

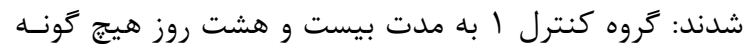

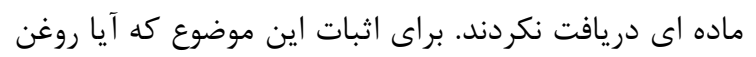

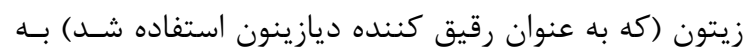

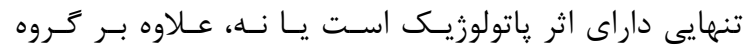

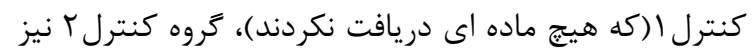

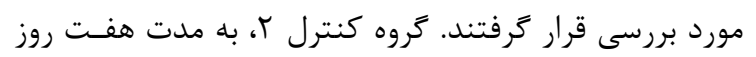

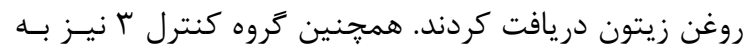

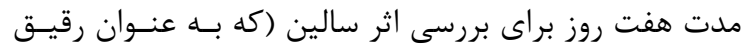

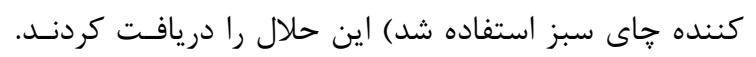

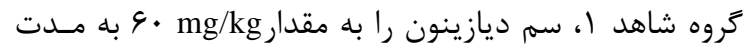

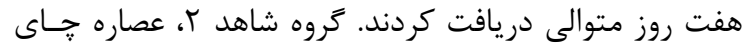

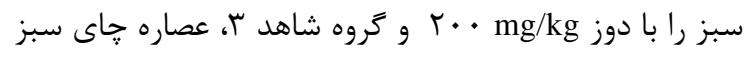

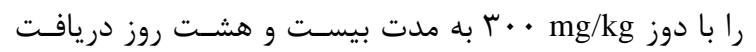

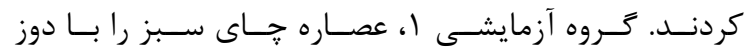

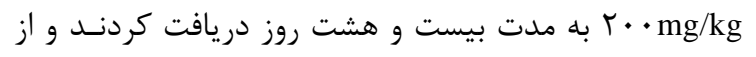

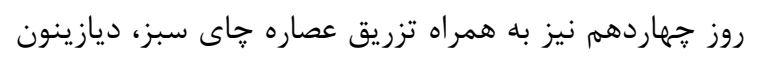

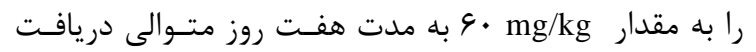

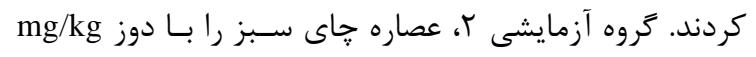

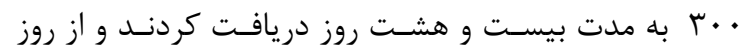

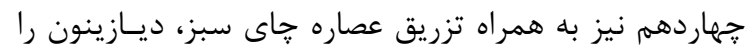

كه توسط مواد شيميايى در كبد ايجـاد مسىشـود جلـوكيرى

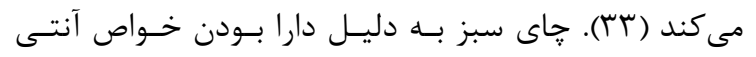

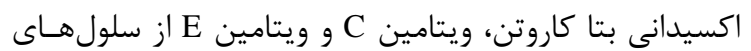

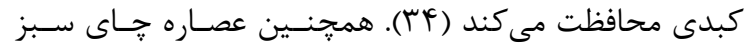

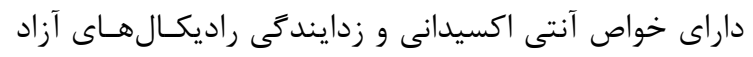

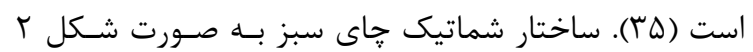

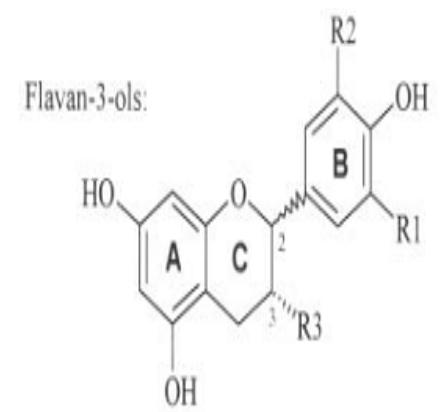

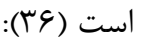

$$
\text { شكل r. نمايى شماتيك از ساختار خاى سبز }
$$

با توجه به اينكه آنتى اكسيدانها از كبد در مقابل راديكـال-

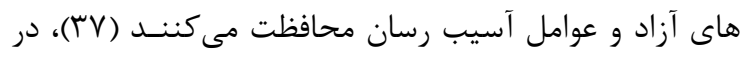

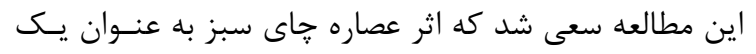

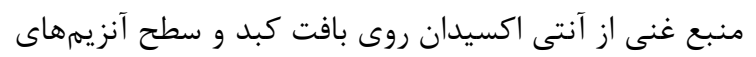

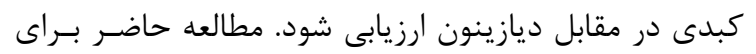

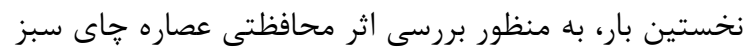

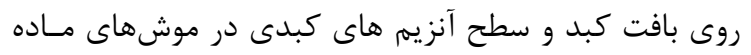

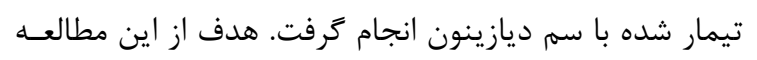

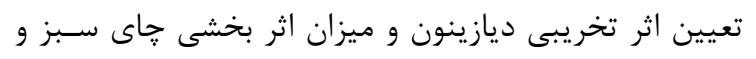

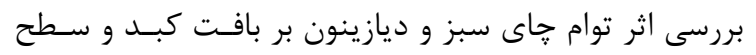

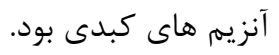

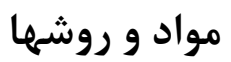
حيوان مورد آزمايش و شرايط نكَهدارى حيوانات

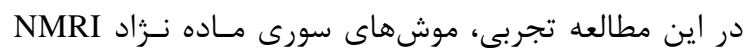

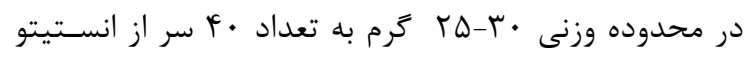

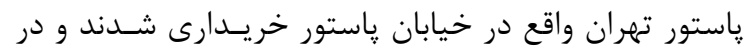

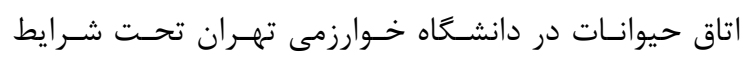

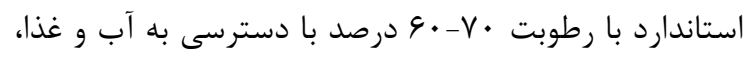

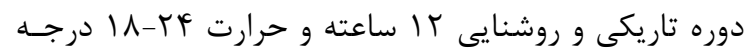

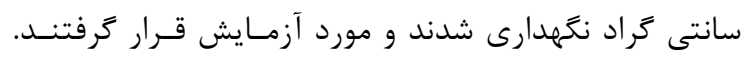

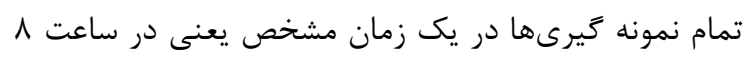

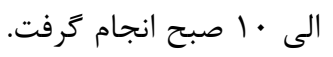


و وآزمون تكميلى توكى تحليل آمارى انجام شـد. (ANOVA)

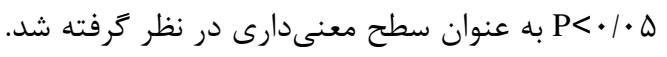

\section{بافته ها}

\section{بر برسى هاى هيستوياتولوزيك}

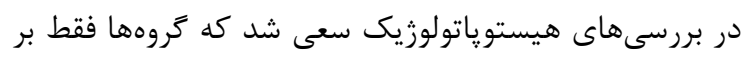

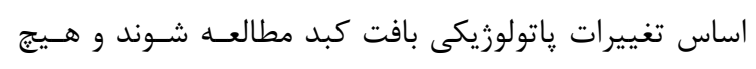

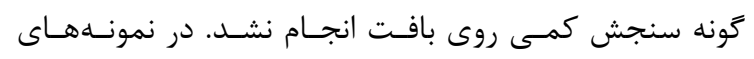

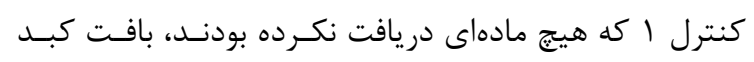

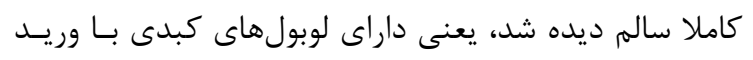

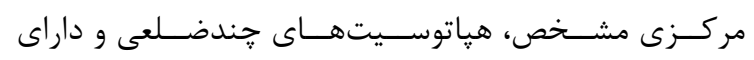

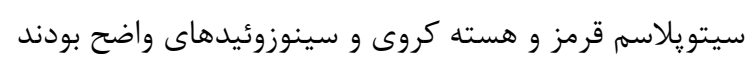

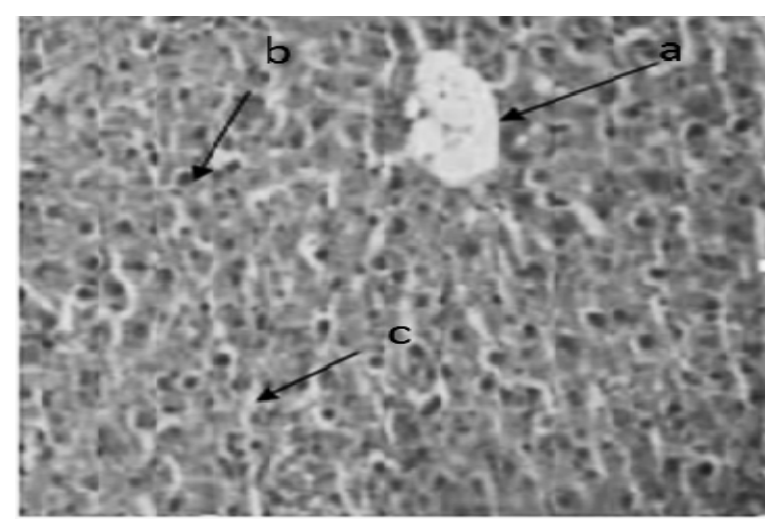

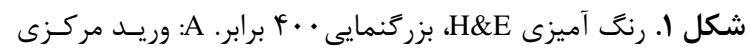

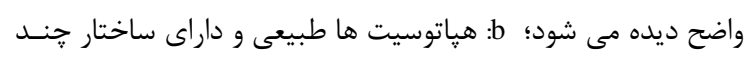

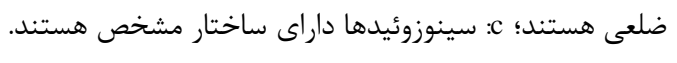

در گروه كنترل r و ب كه به ترتيب روغـن زيتـون و سـالين

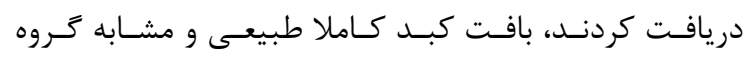

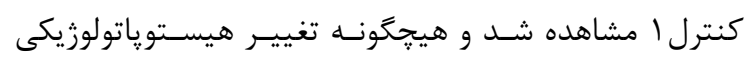

ديده نشد.

در تمام نمونههاى كروه شاهد ا كه سـم ديـازينون دريافت

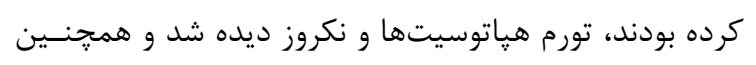

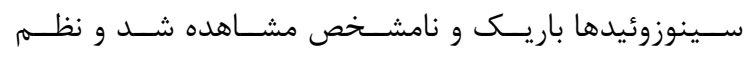

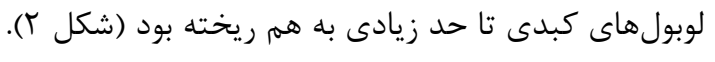

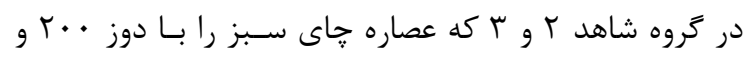

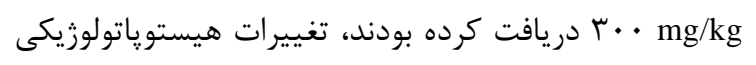

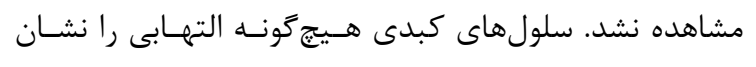

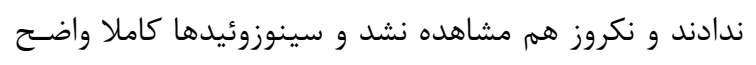

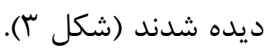

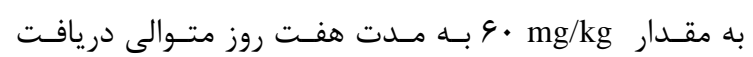
كردند.

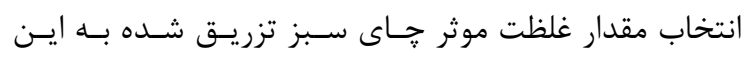

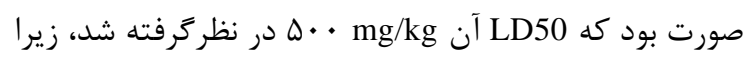

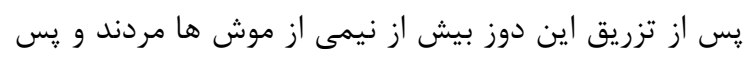

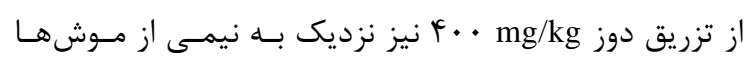

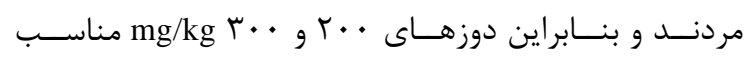

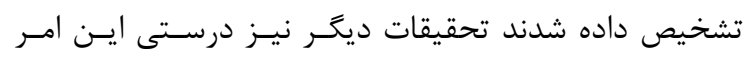

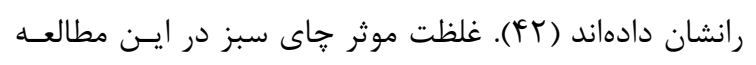

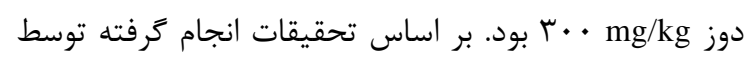

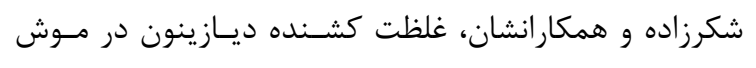

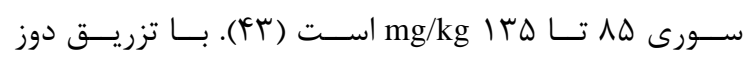

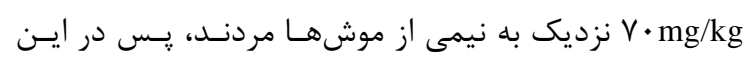

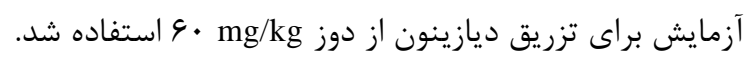

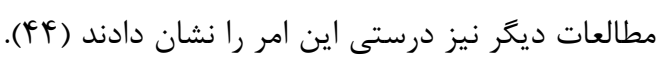

\section{زمان خونَيرى و جداسازى نمونهها}

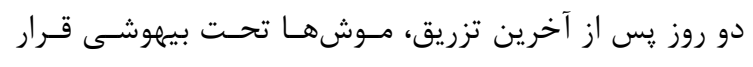

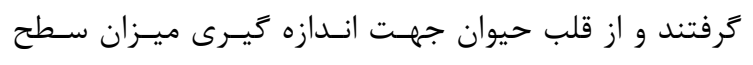

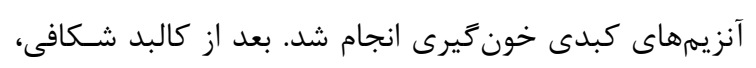

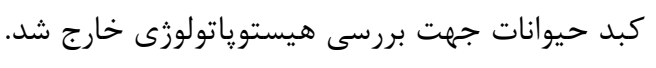
روش بررسى هيستوياتولوزى جيد

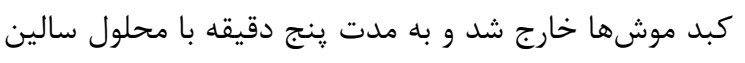

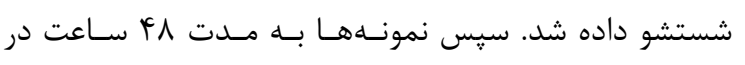

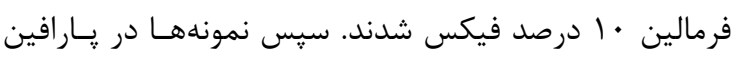

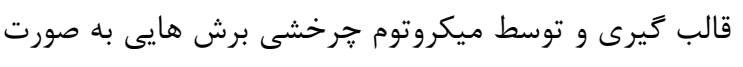

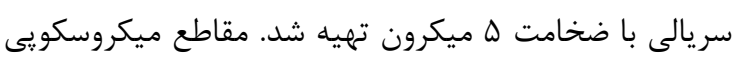

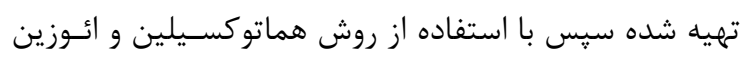

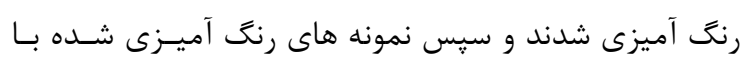

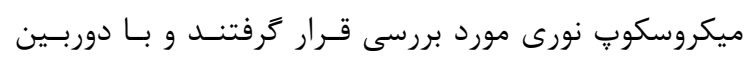
معمولى تصوير تهيه شد. يس از جمع آورى خون، نمونهها به مدت نيم سـاعت در محسيط

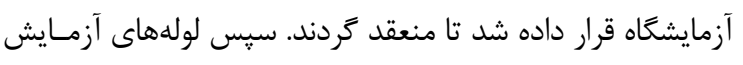

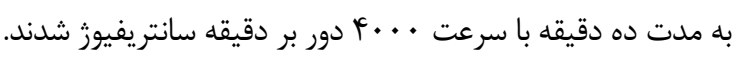

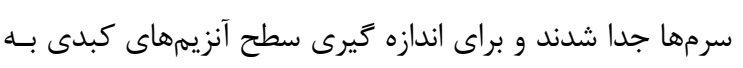
آزمايشعاه تشخيص طبى ارسال شدند. محاسبات آمارى ميانخين و انحراف معيار سطح آنزيمهاى كبد اين هشت كارى

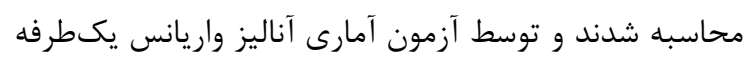


بودند، بافت كبد هيجزَونه التهـاب و نكــروزى را نشـان نـداد

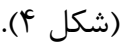
بررسى هاى بيوشيميايى

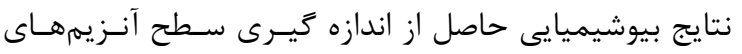
كبد، در اين گروه ها تغييرات معنى دارى را نشان دادئ داد. نتـايج

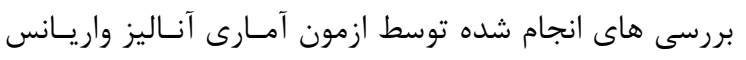
يكطرفه (ANOVA) و آزمون تكميلى تـوكى نشـان داد كــه

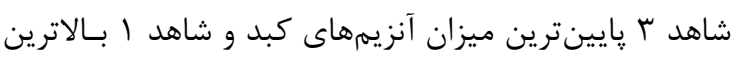
ميزان آنزيمهاى كبدى را دارد، به طورى كه ميانگين ميـزان

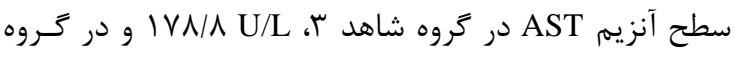

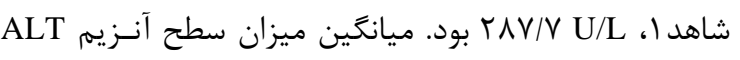

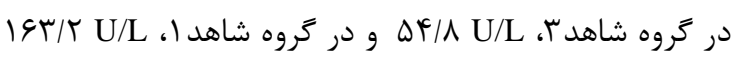

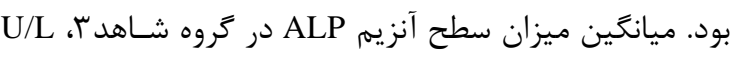

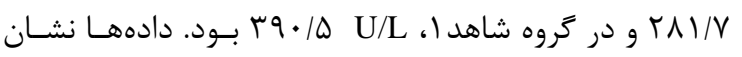

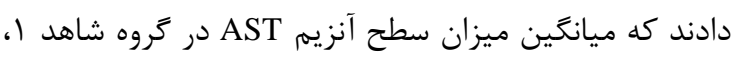

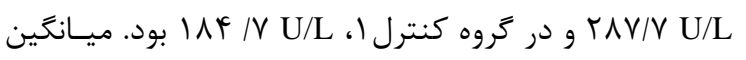

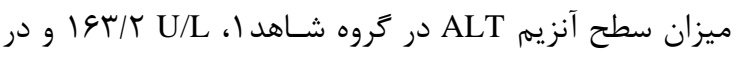

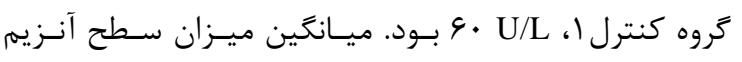

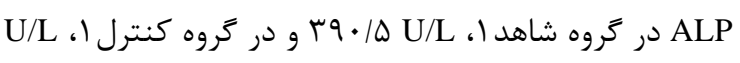

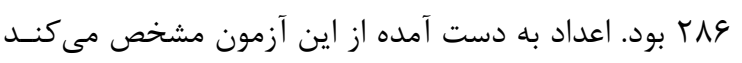

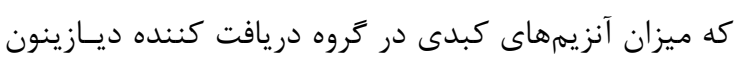

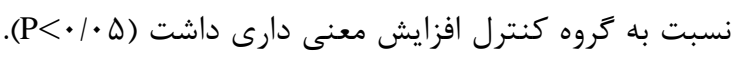

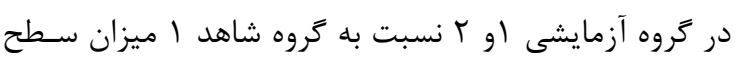

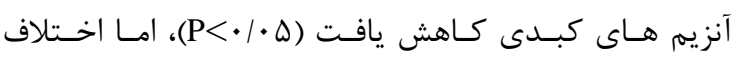

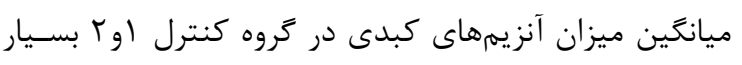

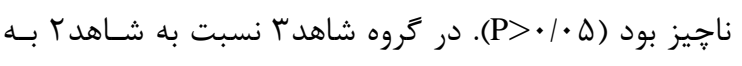
مقدار جزيى نيز كاهش در سطح اين آنزيم هـا ديـده شـــ و و

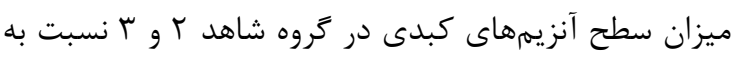
گروه كنترل كاهش يافت ولى اين تفاوتها در ايسن تَروهـهـا

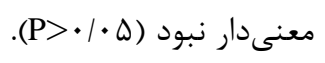

\section{بحث}

امروزه براى كنترل و درمان بيمارىها، بــه طـور كَــترده از

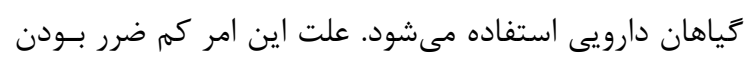

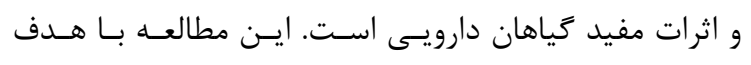

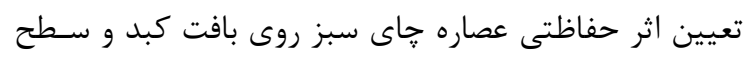

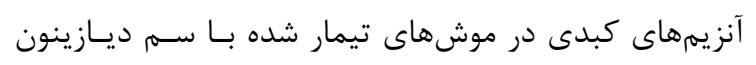

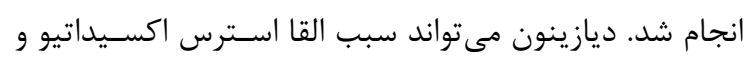

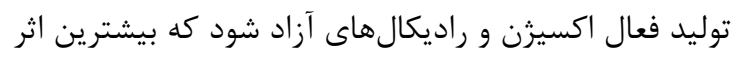

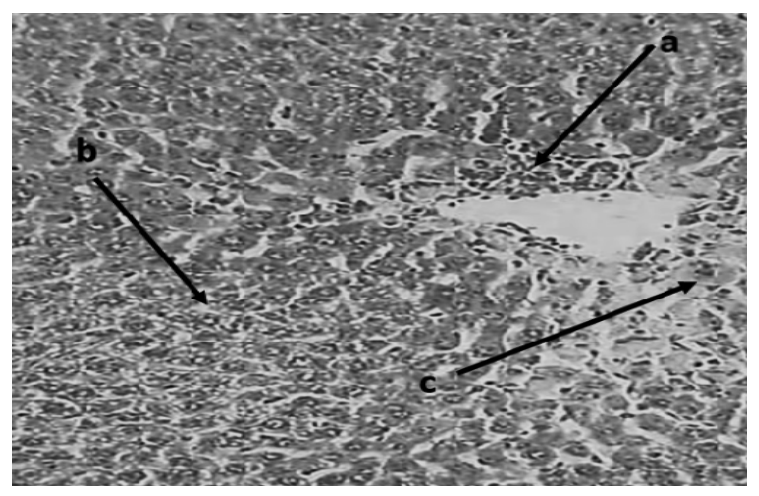

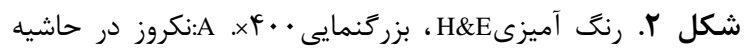

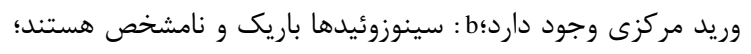

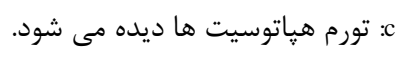

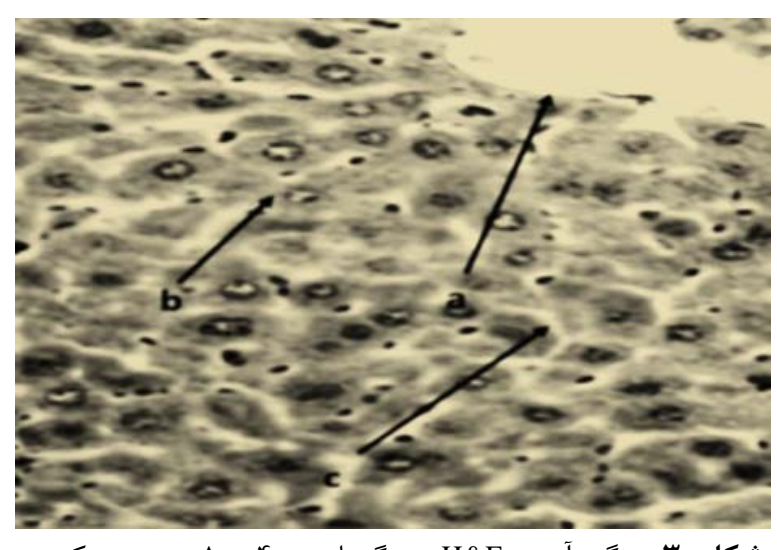

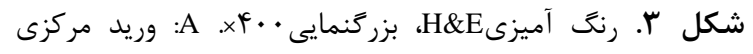

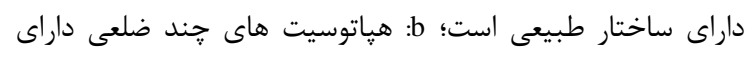

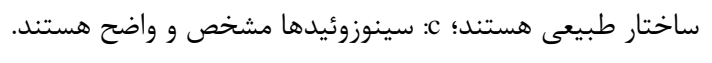

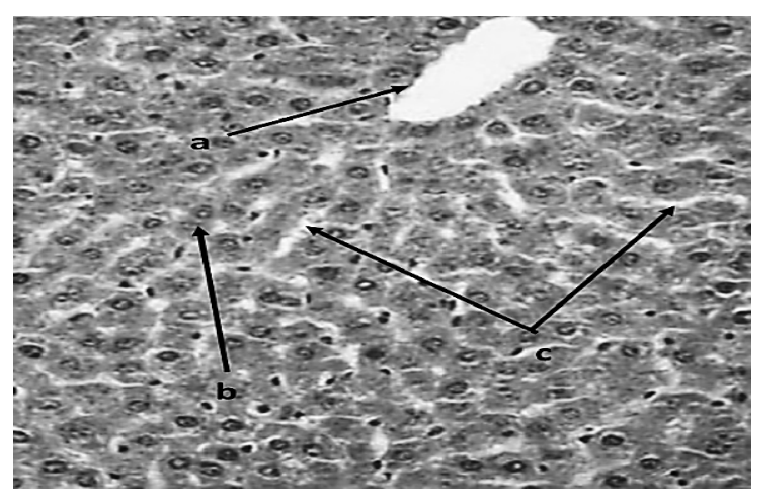

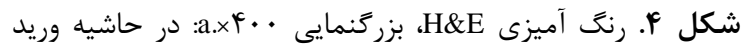

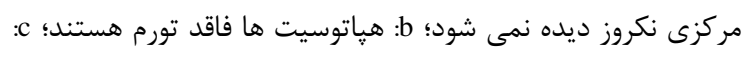

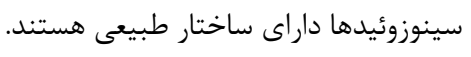

در گروههاى آزمايشى ا و r كه عصاره جاى سبز (به ترتيسب

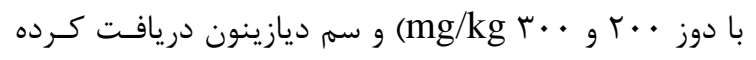




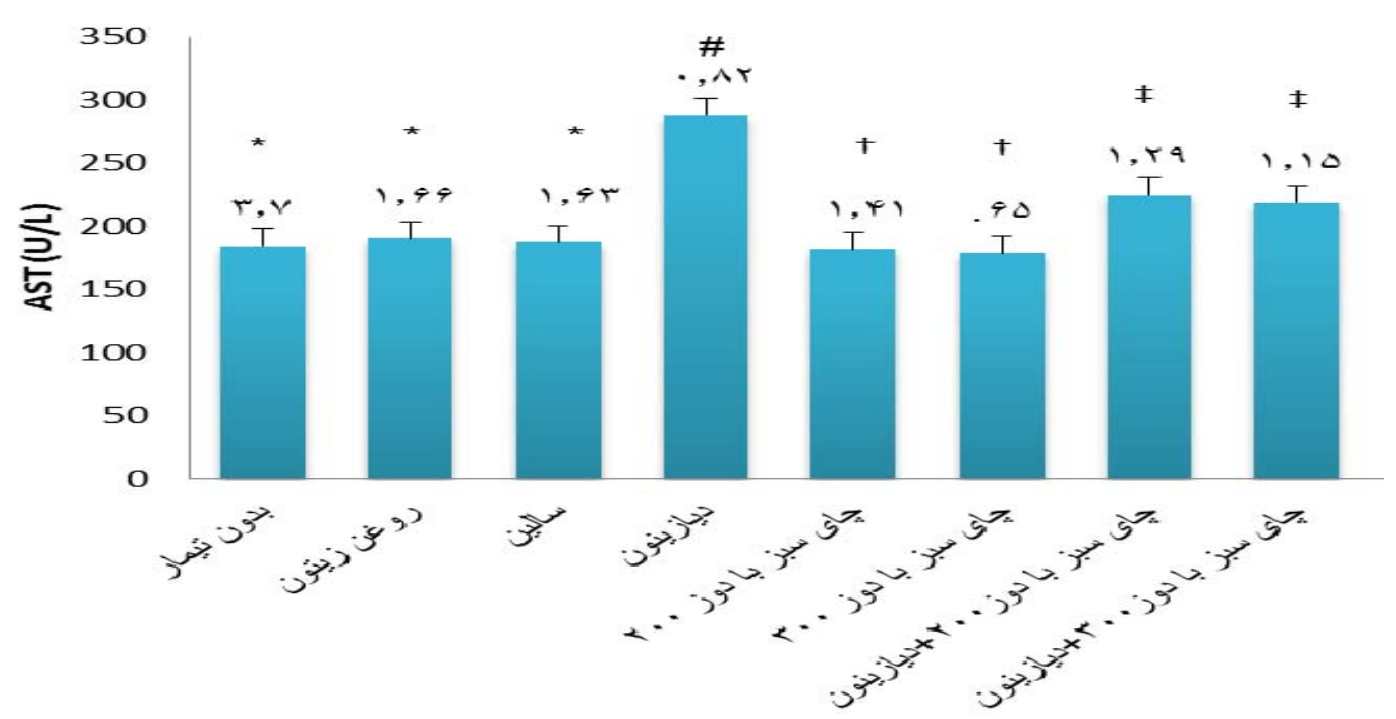

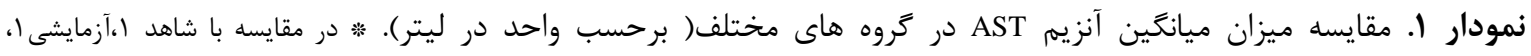

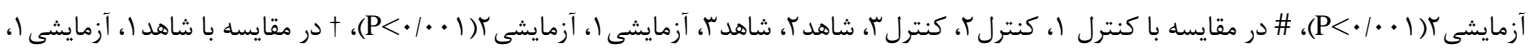

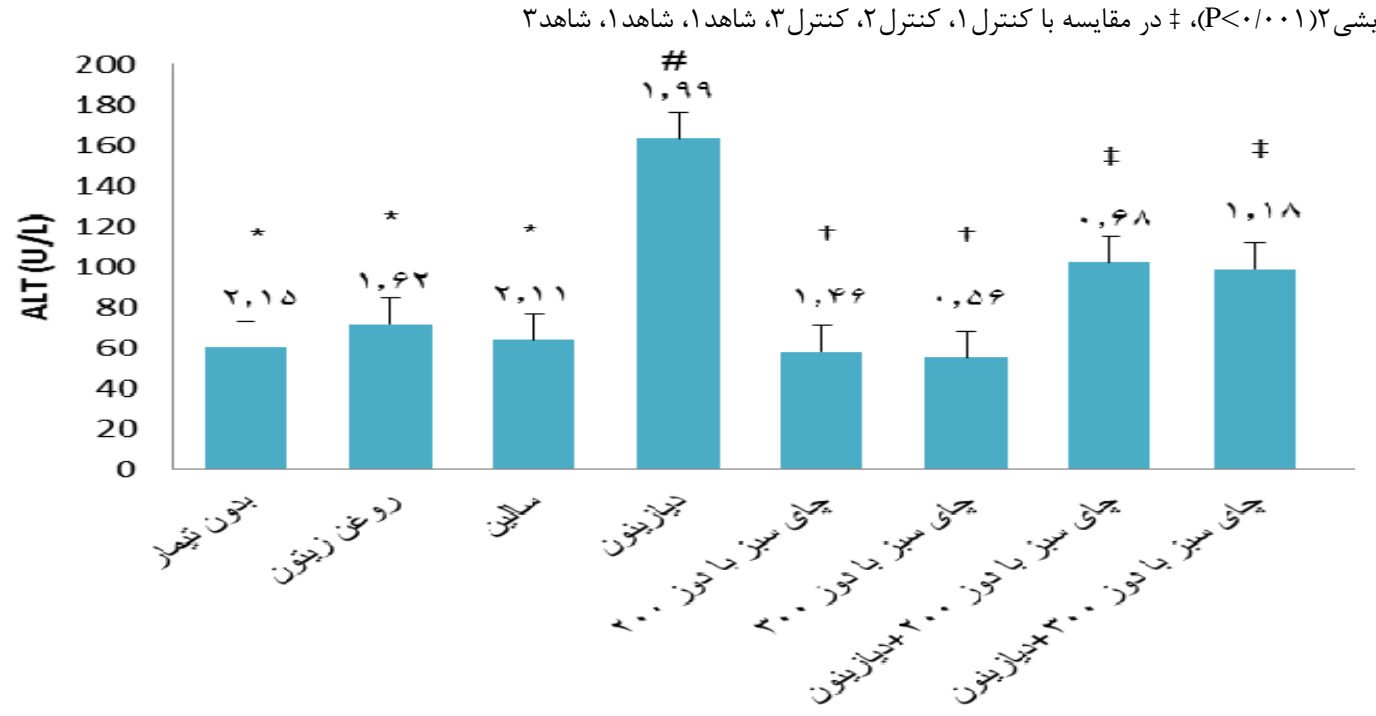

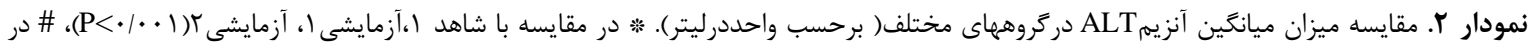

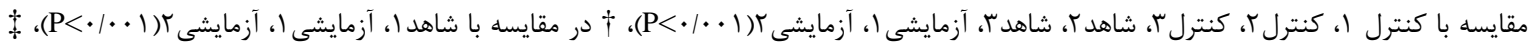

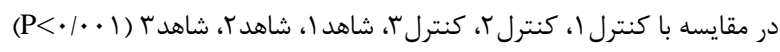

در اين مطالعه نيز در اثر دريافـت سـم ديـازينون، تغييـرات

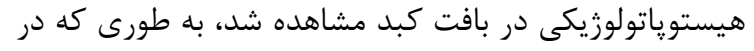

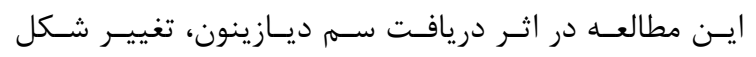

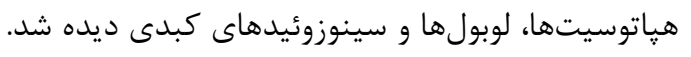

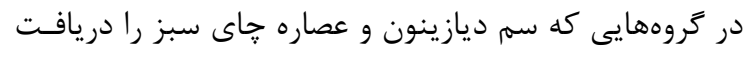

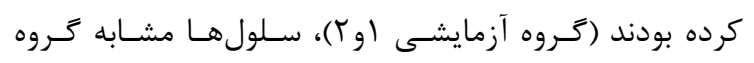

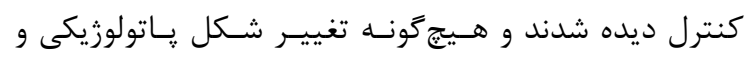

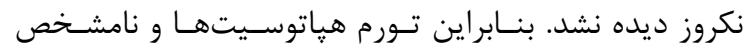

تخريبى ديازينون و راديكالهاى آزاد حاصل از متابوليسم آن

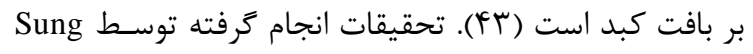

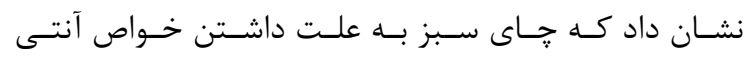

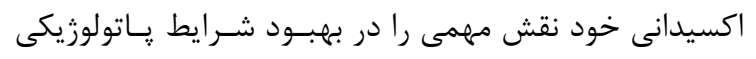

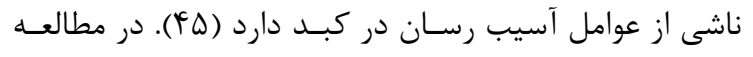

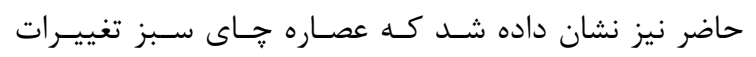

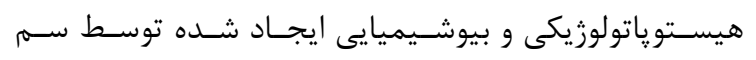
ديازينون را بهبود مىبخشد. 


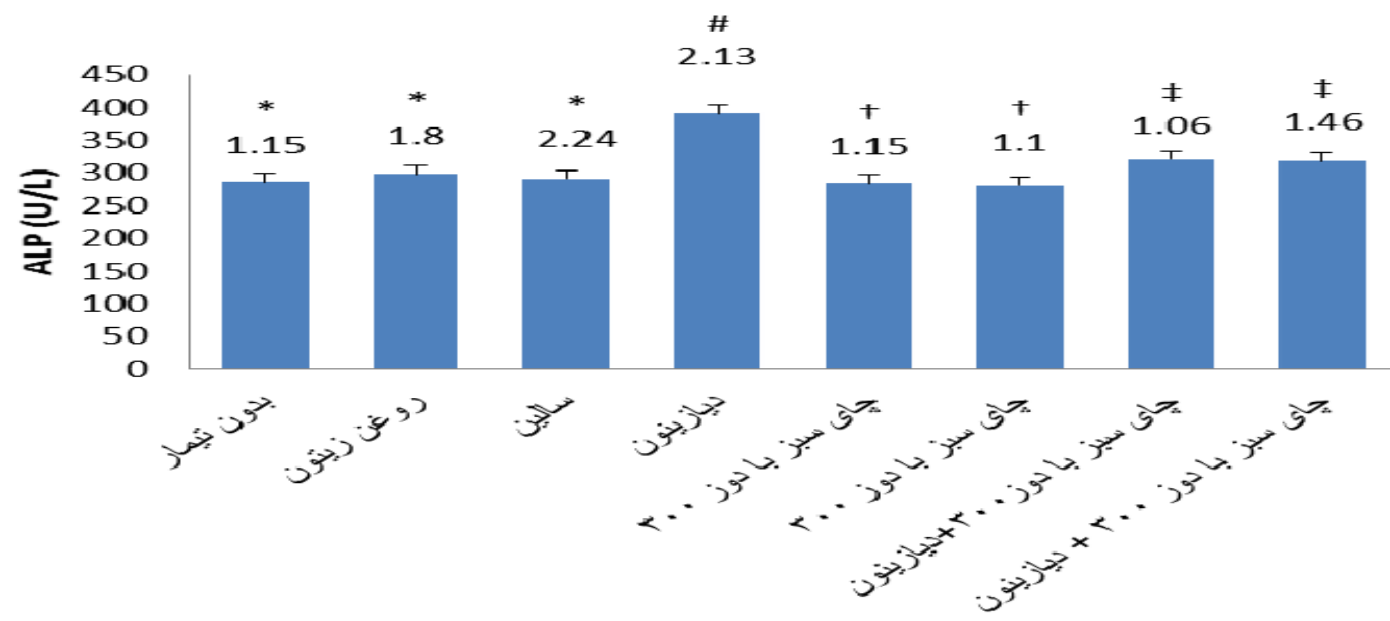

نمودار س. مقايسه ميزان ميانگين آنزيمALP دركروههاى مختلف( برحسب واحد در ليتر). * در مقايسه با شاهد آ،آزمايشى ا،

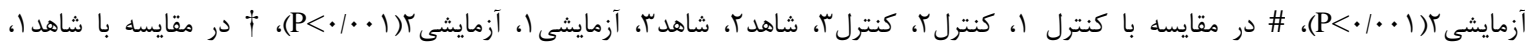

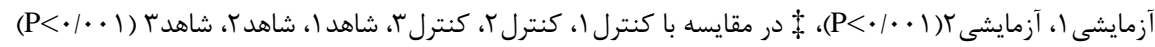

بافتى به كبد و بهبود وضعيت سلولهاى كبدى و افزايش دهنده

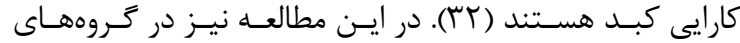

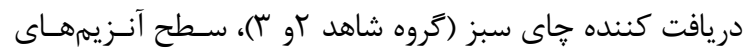

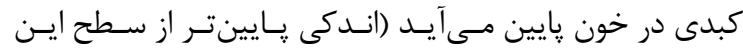

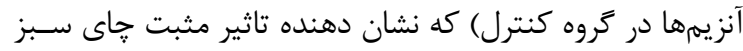
بر افزايش توانايى و كارآمدى كبد و در نتيجه كاهش سطح ايـن دئن فاكتورها در خون است. مطالعات نسبتا زيـادى در مـورد اثرات آترات

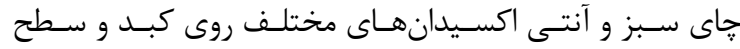

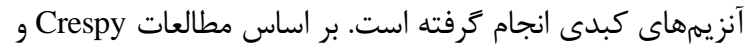

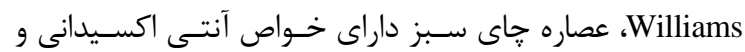

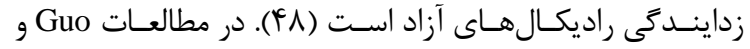

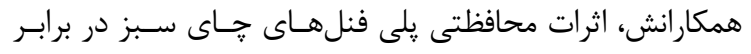

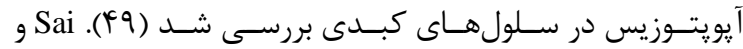
همكارانش اثرات محافظتى خاى سبز را در برابر سميت كبدى و ورئ يروليفراسيون سلولى در كبد موش صحرايى به اثبـات رسـاندند

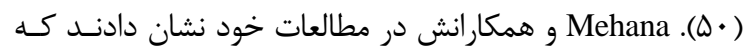

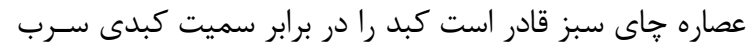

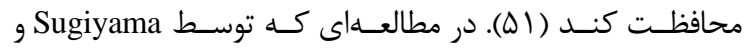

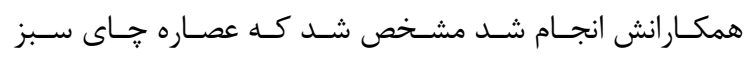

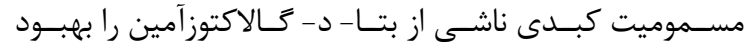

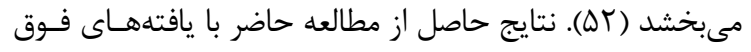

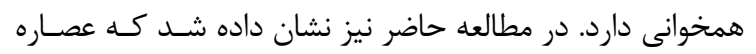

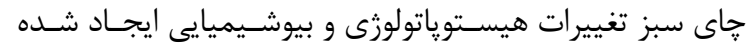

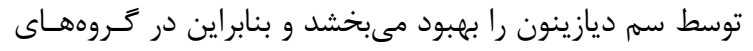

شدن سينوزوئيدها و نامنظم شدن لوبولهاى كبـدى كـه در

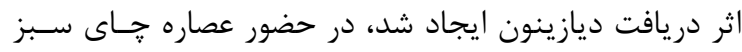

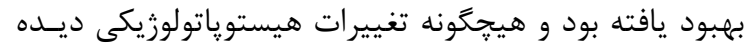
نشد. يكى از مواردى كه مى تواند كاهش عملكرد كبد را نشان

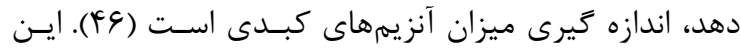

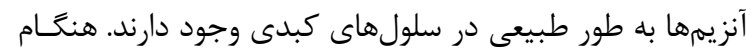
آسيب اين سلولها به علت تورم، نكروز يا تغيير شكل آنها و و يـاــا

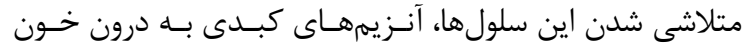

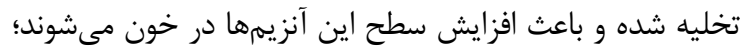

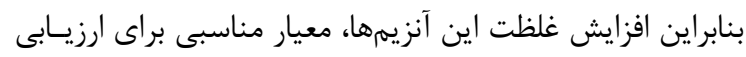

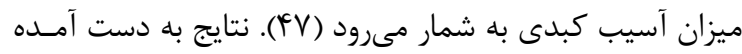

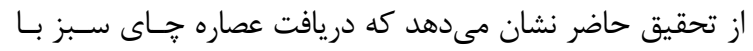
كاهش عمدهاى در افزايش پاتولوزيك اين آنزيمها همــراه اسـت

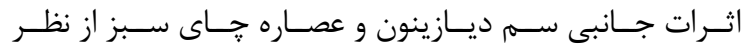

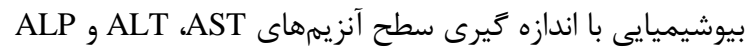

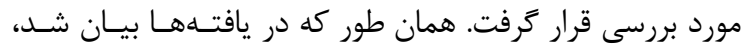

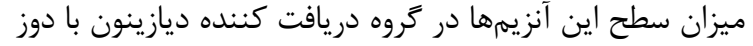

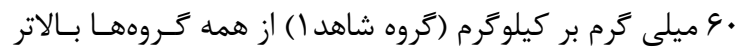

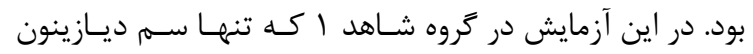

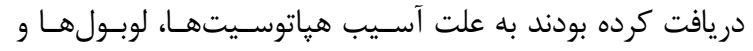

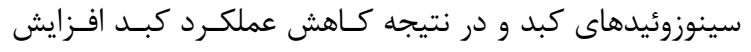

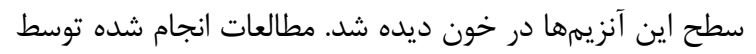

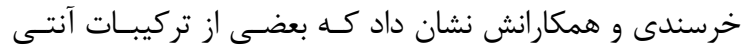

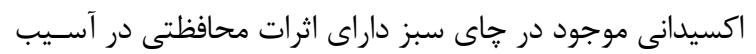


بادرنجبويه باعث كاهش سطح آنزيمهاى كبد مىشـود (DF). در مطالعه ديخرى كه توسط زارع و همكارانش بر روى كياه جاشـير

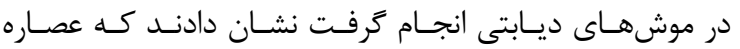

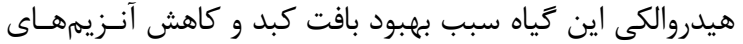

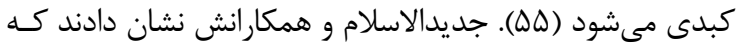

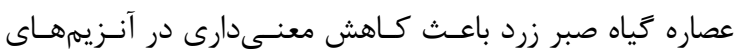

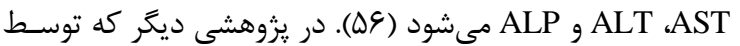

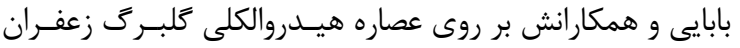

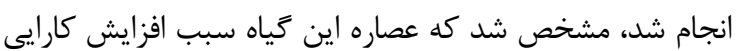
كبد و كاهش سطح آنزيمهاى كبدى مئشـود. در مقايسـهـ بــين

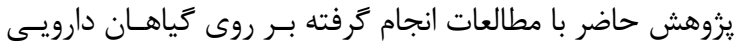

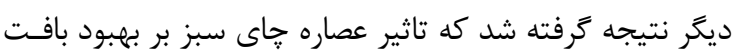

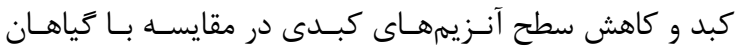

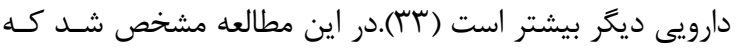

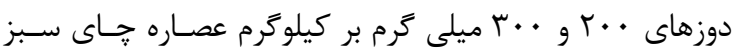
اثرات حفاظتى نزديكى بر سطح آنزيمهاى كبدى دارد و و تفــاوت

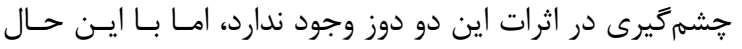

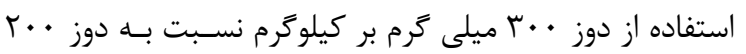

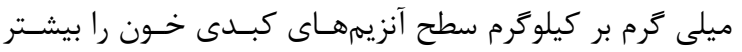
كاهش مى دهد كه نشان دهنده تاثير مثبت بيشـتر ايسن دوز در دري بافت كبد و سطح آنزيم هاى كبدى است دهن دهن

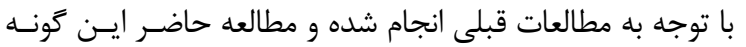
نتيجه كيرى مىشود كه تجويز عصاره خاى سـبز، اثـرات جـانبى

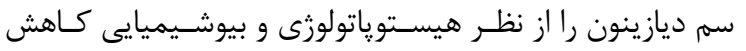

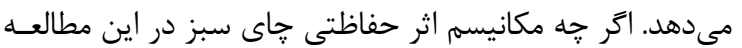

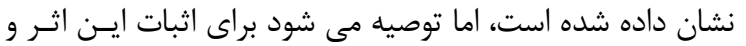

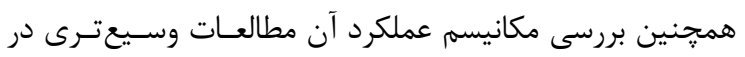
سطح فراساختارى و مولكولى انجام كيرد.
دريافت كننده جاى سبز و ديازينون (كروه آزمايشى او كاني نيـز

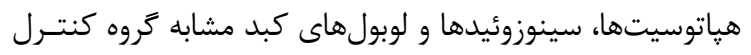

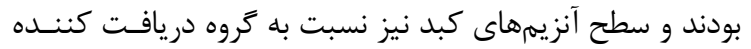

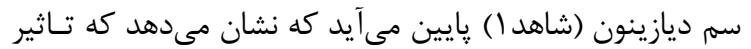

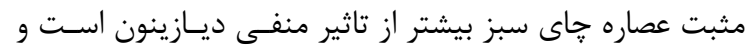

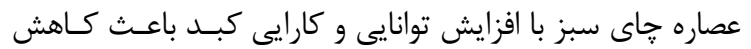

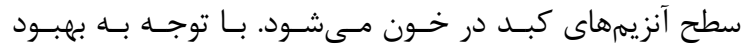

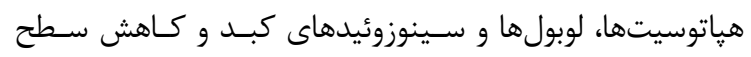

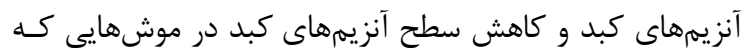

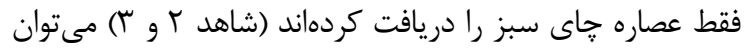

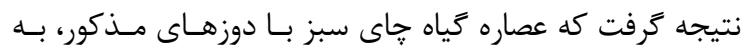

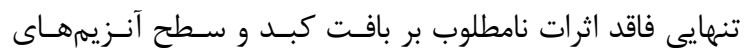
كبدى است. در مطالعات انجام كرفته توسط محققان نشان داده

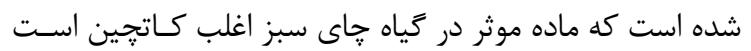

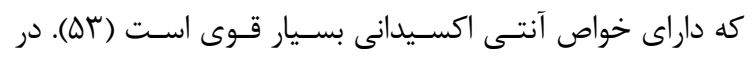

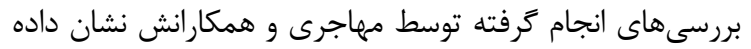

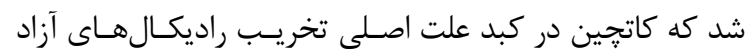

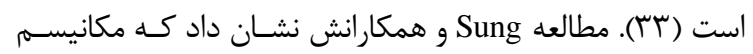

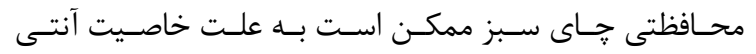

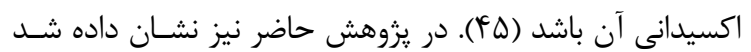

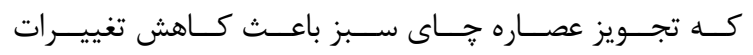
هيستوياتولوزى و بيوشيميايى كبد ناشى از ديازينون مىشـود و

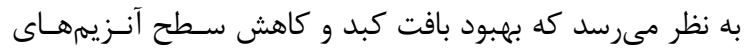

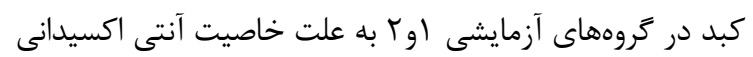

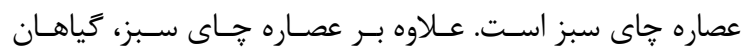

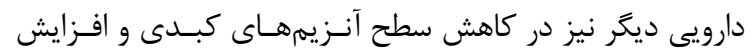

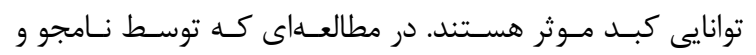
همكارانش انجام شد نشان دادند كـهـ عصـاره هيـدروالكى كيــاه

\section{REFERENCES}

1- Garfitt SJ, Jones K, Mason HJ, Cocker J. Exposure to the organophosphate diazinon: data from ahuman volunteer study with oral and dermal dose. Toxicol Lett 2002;134:105-13.

2- Storm JE, Rozman KK, Doull J. Occupational exposure limits for 30 organophosphate pesticides based on inhibition of red blood cell acetylcholinesterase. Toxicology 2002;150:1-29.

3- Sudakin DL, Power LE. Organophosphate exposures in the united states: a longitudinal analysis of incidents reported to poison centers. J Toxicol Environ Health A 2007;70:141-7.

4- Khanjani M, Poormirza A. Toxicology. Booali Sina University.2005.

5- Peter J, Cherian A. Organic insecticides. Anaesth Intens Care 2000;28:11-21.

6- Shadnia S, Azizi E, Hosseini R, Khoei S, Fouladdel S, Pajoumand A, et al. Evalution of oxidative stress and genotoxicity in organophosphorus insecticide formulators. Hum Exp Toxicol 2005;24:439-45.

7- Zhang H, Sultafos L. Biotransformation of the organophosphorus insecticides parathion and methyl effect oof black tea extract. Clin Chim Acta 2005;358:1-138. 
8- Chambers J, Oppenheimer SF. Organophosphates, serine esterase inhibition, and modeling of organophosphate toxicity. Toxicol Sci 2004;77:185-7.

9- Girdano G, Afsharine Z, Guizzetti M, Vitalone A, Kavanagh TJ, Costa LG. Organophosphorus insecticides chlorpyrifos and diazinon and oxidative stress in neuronal cells in a genetic model of glutathione deficiency. Toxicol Appl Pharmacol 2007;219:801-900.

10- Hariri AT, Moallem SA, Mahmoudi M, Hosseini Zadeh H. The effect of crocin and safranal, constituents of saffron, against subacute effect of diazinon on hematological and genotoxicity indices in rats. Phytomedicine 2011;18:449-504.

11- Winterbourn CC, Hawkins RE, Brian M, Carrel RW. The estimation of red cell superoxide activity. J Lab Clin Med 1975;85:337-41.

12- Garfitt SJ, Jones K, Mason H, Cocker J. Exposure to the organophosphate diazinon: data from a human volunteer study with oral and dermal doses. Toxicol Lett 2002;134:105-13.

13- Kalender S, Ogutcu A, Uzunhis M, Acikgoz F, Durak D. Diazinon-induced hepatotoxicity and protective effect of vitamin E on some biochemical indices and ultrastructural changes. Toxicology 2005;211:197-206.

14- Meister A. Glutathione metabolism. Methods Enzymol 1995;251:3-7.

15- Cruc E. Effects of diazinon on antioxidant defense system and lipid peroxidation in the liver of cyprinus carpio. Environ Toxicol 2010;26:571-8.

16- Jafari M, Salehi M, Asgari A, Ahmadi S. Effects of paraoxon on serum biochemical parameters and oxidative stress induction in various tissues of wistar and Norway rats. Environ Toxicol Pharmacol 2012;34:876-87.

17-Ranjbar A, Pasalar P, Abdollahi M. Induction of oxidative stress and acetyl cholinesterase inhibition in organiphosphorous pesticide manufacturing workers. Hum Exp Toxicol 2002;21:179-82.

18-Hansch C, Mckarns S, Smith C, Dodittle D. Comparative QSAR evidence for a free-radical mechanism of phenolin duced toxisity. Chem Biol Inter 2000;127:61-72.

19- Giannini E, Testa R, Savarino V. Liver enzyme alternation: a guide for clinicians. CMAJ 2005;172:367-79.

20- R Dehghani, B Fathi, Z Aboo-Saaidi, A Jalalati, M Ramezani, M Nohi. Epidemiology of Poisonings in Shahid Beheshti

Hospital in Kashan, Iran. IJMTFM 2015;5.

21- Ogle N. Green tea Camellia Sinensis. J Australian Herbalism 2009;21:7-44.

22- Demeule M, Levesque J, Annabi B, Gingras D. Green tea catechins as novel antitumor and antiangiogenic compound. Curr Med Chem 2002;2:441-63.

23- Brown D. Green tea (camellia sinensis) extract and its possible role in the prevention of cancer. Altern Med Rev 1999;4:360-70.

24- Sato K, Sueoka K, Tanigaki R, Tajima H, Nakabayashi A, Yoshimura Y, et al. Green tea extract attenuate doxorubicin-inducced spermatognic disorders in conjunction with higher telomerase activity in mice. J Assist Reprod Genet 2010;27:501-8.

25- Singh M, Tyagi S, Bhui K, Prasad S. Regulation of cell growth through cell cycle arrest and apoptosis in HPV. Ann Pharmacol 2009;33:17-30.

26- Thangapazham R, Passi N, Maheshwari RK. Green tea polyphenol and Epigallocathecin gallate induced apoptosis and inhibit invasion in human breast cancer cells. Cancer Biol Ther 2007;6:1938-43.

27- Tsuneki H, Ishizuka M, Terasaw M, Wu JB, Sasaoka T, Kimura L. Effect of green tea on blood glucose levels and serum proteomic patterns in diabetic (db/db) mice and on glucose metabolism in healthy humans. BMC Pharmacol 2004;4:18.

28- Tokimitsu I. Effects of tea catechins on lipid metabolism and body fat accumulation. Biofactors 2004;22:141-3.

29- Luo T, Wang J, Yin Y, Hua H, Jing J, Sun X, et al. epigallocatechin gallate sensitize breast cancer cells to paclitaxel in a murine model of breast carcinoma. Breast Cancer Res 2010;12:R8.

30- Tahssein A, Dawser K, Shawi N. The possible protective effect of different concentrations of Aqueous green tea extract (AGTE) Against Hepatic Toxicity induced by DDT rats. J Pharm Sci 2011;2:157-67.

31-El-Beshbishy HA. Hepatoprotective effect of green tea (Camellia sinensis) Extract against Tamoxifen-induced Liver Injury in Rats. J Biochem Mol Biol 2005;38:563-70.

32- Khorsandi LS, Javadnia F, Orazizadeh M, Abd Elahi M. Effect of green tea extract on acetaminophen induced acute hepatotoxicity in mice. Iranian Journal of Medicinal and Aromatic Plants 2010;26:9-22. 
33- Sano M, Takahashi Y, Yoshino K, Shimoi K, Nakamura Y, Tomita I, et al. Effect of tea on lipid peroxidation in rat liver and kidney: a comparision green and black tea feeding . Biol Pharm Bull 1995;18:1006-8.

34- Pietta P, Simonetti P, Gardana C, Brusamolino A. Catechin metabolites after intake of green tea infusions. Biofactors 1998;8:111-8.

35- Rice-Evans C, Miller N. Measurement of the ontioxidant status of dietary constituents, low-density lipoproteins and plasma. Prostaglandins Leukot Essent Fatty Acids 1997;57:449-505.

36- Jamshidi Z, Taheri E, Mohammadi M, Kohseni Kouchesfehani H. The protective effect of green tea extract on kidney tissues and blood factors of kidney functions in male mice treated with paclitaxel. J Med Plants 2017;16:47-59.

37- Frei B, Higdon JV. Antioxidant activity of tea polyphenols in vivo: evidence from animal studies. J Nutr 2003;133:3275S84.

38- Perva A, Skerget M, Knez Z, Weinreich B . Extraction of active ingredients from green tea (Camellia sinensis): Extraction efficiency of major catechins and caffeine. Food Chem 2006;96:597-605.

39- Ahmadian N, Azhdari H, Ruzeh S. Antinociceptive effect of hydroalcoholic extract of green tea in male mice. KUMS 2014;597-605.

40- Heidari E, Ghoreishi M. Experimental Optimization of Modified Supercritical Extraction of Epigallocatech in Gallate from Green Tea with Ethanol Co- Solvent. J Sep Sci Engineering 2012;39-48.

41- Mohseni KH, Nabiuni M, Mortazavi Asl SS, Nazari Z, Amiri F. Effect of green tea hydro alcoholic extract on aquaporin4 expression in cerebral cortex, as a potential therapeutic way to alleviate edema symptoms. J Cell Tissue 2014;5:309-16.

42- Kenji S, Kou S, Reiko T, Hroto T. Green tea extracts attenuate doxorubicin-induced spermatogenic disorders in conjunction with higher telomerase activity in mice. J Assist Reprod 2010;27:501-8.

43- Shokrzadeh M, Ahangar N, Abdollahi M, Shadboorestan A, Omidi M. Diazinon effects on hepatic glutathione levels in rats and protective role of selenium on L-Carnitine. J Mazand Univ Med Sci 2012;22:8-31.

44- Hajigholamali M, Jafari M, Hajihosseini R, Asgari A. Evaluation of oxidative stress biomarkers of rat liver exposed to acute doses of diazinon. JQUMS 2011;15:9-20.

45- Sung H, Nah J, Chum S, Park H, Yang SE, Min WK. Invivo antioxidant effect of greentea. Eur J Clin Nutr 2005;4:527-9.

46- Kim WR, Flamm SL, Di Bisceglie AM; Public Policy Committee of the American Association for the Study of Liver Disease. Serum activity of alanine aminotransferase as an indicator of health and disease. Hepatology 2008;47:1363-70.

47- Kramer J, Hoffman W. Clinical biochemistry of domestic animals. Academic Press 1997;303-57.

48- Crespy V, Williamson G. Areview of the health effects of green tea catchins in invivo animal models. J Nutr 2004;134:3431-40.

49- Guo Q, Zhao B, Li M, Shen S, Xin W. Studies on protective mechanism of four component of green tea polyphenols against lipid peroxidation in synaptosome. Biochim Biophys Acta 1996;1304:210-22.

50- Sai K, Kai S, Umemora T, Tanimora A, Hasegava R, Inoue T, et al. Protective effect of green tea on hepatotoxisity, oxidative DNA damage and cell proliferation in the rat liver induced by repeat oral administration of 2-nitropropane. Food Chem Toxicol 1998;36:1043-51.

51- Mehana EE, Meki AR, Fazili KM. Ameliorated effects of green tea extract on lead induced liver toxisity in rats. Exp Toxicol Pathol 2012;64:291-5.

52- Sharangi AB. Medicinal and therapeutic potentialities of tea (camellia sinensis L.). food Res 2009;42:529-35.

53- Namjoo A, Mirvakili M, Rafieian-Kopaei M. Histopatological and biochemical effects of subcute toxisity of lemon balm hydroalcoholic extract on liver and kidney tissues in the surri mice. J Shahrekord Univ Med Sci 2013;15:62-72.

54- Zare T, Mokhtari M, Mohammdi J. The effect of hydroalcoholic extracts of prangos ferulacea on blood factors of kidney and liver function in diabetic male wistar rats. J Fasa Univ Med Sci 2012;2:174-80.

55- Jadidoleslame M, Shahraki M, Abasnejad M. The survey of aleovera agueous extra and glibenclamid interaction on blood glucose, LFT and lipids diabetic induced male rats by streptozotocin. J Rafsanjan Univ Med 2011;9:185-94.

56- Babaei A, Arshami J, Haghparast A, Danesh Mesgaran M. Effects of crocus sativus extract on biochemical blood parameters in male rats. J Arak Univ Med Sci 2013;16:14-21. 